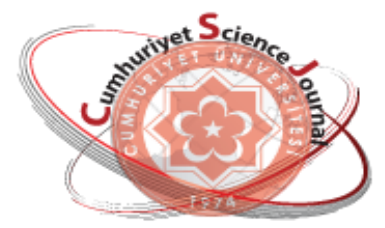

e-ISSN: $2587-246 X$

ISSN: $2587-2680$

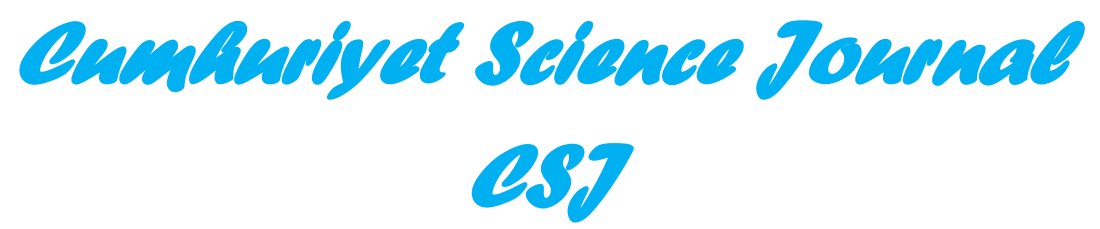

Cumhuriyet Sci. J., Vol.39-2(2018) 375-379

\title{
Polarization Effects In Hadron-Hadron Scatterings
}

\author{
I.G. AFANDIYEVA, R.A. AHMEDOV* \\ Azerbaijan State University of Oil and Industry Baku, AZERBAIJAN \\ Received: 15.01.2018; Accepted: 30.05.2018 \\ http://dx.doi.org/10.17776/csj.379066
}

\begin{abstract}
In the case of diffraction scattering of hadrons by hadrons, a nonzero polarization of the scattered particles arises, which is related to the logarithmic derivative of the differential scattering cross section. Polarization changes sign in those reactions whose angular distributions contain the second diffraction maximum. On the basis of the assumption on the diffraction behavior of the quark amplitudes, it can be concluded that the quark scattering amplitude on the quark exhibits only the first principal maximum, the amplitude of annihilation scattering of quarks exhibits two maxima. This fact allows the behavior of polarizations of finite baryons as a function of the momentum transfer, and also obtains a relation between the polarizations of baryons in various reactions. The polarization sign is determined by the nature of the spin-orbit interaction: for the repulsive and attraction potential, there must be opposite signs the polarization. The polarization of the recoil particles vanishes, where the differential cross sections have a minimum.
\end{abstract}

Keywords: Diffraction, polarization, hadrons, quark, differential cross section.

\section{Hadron-Hadron Saçılımlarında Polarizasyon Etkileri}

\begin{abstract}
Özet: Hadronların hadronlar tarafından kırınım dağılması durumunda, dağınık parçacıkların sıfır olmayan bir polarizasyonu ortaya çıkmaktadır ki bu, difüzyon saçılma kesitinin logaritmik türevi ile ilgilidir. Polarizasyon değişiklikleri, açısal dağılımları ikinci kırılma maksimumunu içeren reaksiyonlarda imzalar. Kuark amplitüdlerinin difraksiyon davranışı üzerine yapılan varsayımlara dayanarak, kuarktaki kuark saçılma genliğinin sadece ilk ana en yüksek değeri, kuarkların imha saçılmasının genliğinin iki maksimuma sahip olduğu sonucuna varılabilir. Bu gerçek, sonlu baryumların polarizasyonlarının momentum aktarımının bir fonksiyonu olarak hareket etmesine izin verir ve ayrıca çeşitli reaksiyonlardaki biyonların kutuplaşmaları arasında bir ilişki kurar. Polarizasyon işareti spin-yörünge etkileşiminin doğasıyla belirlenir: itme ve çekim potansiyeli için, kutuplaşmanın zıt işaretleri olmalıdır. Diferansiyel kesitlerin minimum olduğu yerlerde, geri tepme partiküllerinin polarizasyonu ortadan kalkar.
\end{abstract}

Anahtar Kelimeler: Kırınım, polarizasyon, hadronlar, kuark, diferansiyel kesit.

\section{INTRODUCTION}

At the present time the theoretical and experimental research leads to the conclusion about the essential role of the spin of particles in the high energy scattering. The specific feature of this kind of reaction is that the transition amplitude is in general a sum of several nucleon contributions, each with its own phase and amplitude. This makes a basis for the hypothesis about the existence of a non-zero polarization research on the future accelerators will provide information about the structure of the nucleon interaction at large distances.

The analysis shows that when the preasymptotic corrections are absent, we have zero polarizations. The parameters in the spin-flip amplitude determined from one reaction, for example nucleon-nuclei scattering, allow us to obtain a wide circle of results for the polarization effects of elastic, nucleon-nuclei,

\footnotetext{
* Corresponding author. Email address: rasim.a15@mail.ru

http://dergipark.gov.tr/csj C2016 Faculty of Science, Cumhuriyet University
} 
$p p$ or meson-nucleon scattering at high energies. In this paper we consider the model results for the polarization effects of protonnuclei scattering at high energies. The spinpolarization effects are used not only as battle probes for determining the accuracy of the model employed, but also play a critical role in understanding the spin-dependent interactions involved in the collision dynamics $[1,2]$.

Early, it was shown [3] that the calculated real and imaginary parts in the quark cluster model of the leading asymptotic term of the spin-flip amplitude of the charge exchange reactions agree sufficiently well with the amplitude reconstructed by the model independent approach from the experimental data. In the framework of the hypothesis concerning the existence of quark bag in nuclei we managed to describe the behavior of the formfactors of nuclei at large $q$ and structure functions of nuclei.

\section{THE MODEL FORMALISM}

At intermediate energies (from hundreds of $\mathrm{MeV}$ to $1 \mathrm{GeV}$ ) the interaction of hadrons with nuclei can be studied as the optical model and in the framework of the diffraction theory of multiple scattering Glauber-Sitenko (GS) [4]. GS theory is limited by two main approximations: eikonal and adiabatic, which allows applying it only to the scattering of high-

$$
\Psi_{{ }^{12} C}=\phi_{N_{1}}\left(r_{1}, r_{2}, r_{3}\right) \cdots \phi_{N_{12}}\left(r_{34}, r_{35}, r_{36}\right) \chi\left(R_{1}, R_{2}, \ldots, R_{12}\right),
$$

where the nucleus is pictured as a bag with radius $R_{h}$, located at $R_{\mathrm{A}}$ enclosing $A$ nucleons. Using the relations

$$
R=\frac{r_{3 i-2}+r_{3 i-1}+r_{3 i}}{3}, \mathrm{i}=1,2, \ldots, 12
$$

and

$$
\phi(r)=\left(\sqrt{\pi} R_{h}^{2}\right) \exp \left(-r^{2} / R_{h}^{2}\right) .
$$

Fourier transform of the amplitude has the following form [5]:

$$
f(q)=(i k / 2 \pi) \int d \mathbf{b} \exp (i \mathbf{q} \mathbf{b})\left(\delta_{m n} \delta_{M N}\right)-\operatorname{Det} \mid \delta_{m n} \delta_{M N}-\left\langle M\left|\prod_{i=1}^{3} \prod_{j=1}^{3}\left(1-\gamma\left(\mathbf{b}-\mathbf{s}_{i}+\mathbf{r}_{j}\right)\right)\right| N\right\rangle .
$$


Here $\mathbf{q}$ is the momentum transfer, $\mathrm{k}$ is the value of the wave vector of the nucleon, $\mathbf{b}$ is the impact-parameter vector, $\gamma(\mathbf{b}-\mathbf{s}+\mathbf{r})$ is the profile function for the nucleon-nucleon interaction, brackets $\langle\|\rangle$ mean interactions over the nucleon coordinates. The matrix element of the profile function between the single particle states described by the quantum numbers $M$ and $N$.

At sufficiently high energies of the relative motion of the colliding nucleons, we can confine ourselves to the first Born approximation. The scattering amplitude $f$ is elements of the $2 \times 2$ matrix, which can be expressed in terms of the Pauli matrices $\sigma$ and the identity matrix $E$

$$
f=g \mathrm{E}+(\mathbf{h} \boldsymbol{\sigma}) .
$$

In (5), the factor $g$ corresponds to an interaction independent of spin, and the vector $h$ to the interaction causing the reorientation of the spin [6].

Assume that the particle beam with the wave vector $\mathbf{k}$ is scattered by the nucleus $A$ in the direction and the angle between the direction of the vector $\mathbf{k}$ and $\mathbf{k}^{\prime}$ equal to $\theta_{1}$. The scattered beam is polarized in the direction of $\mathbf{n}_{1}$, which is perpendicular to the plane $\mathbf{k}$ and $\mathbf{k}^{\prime}$. Broken particle falls on the second core $B$ in and dispersed in the direction $\mathbf{k}^{\prime \prime}\left(\theta_{2}, \varphi_{1,2}\right)$, where $\theta_{2}$ - the angle between the vectors $\mathbf{k}^{\prime}$ and $\mathbf{k}^{\prime \prime}$, and $\varphi_{1,2}$ - the angle between the vectors $\mathbf{n}_{1}$ and $\mathbf{n}_{2}$, and perpendicular to the planes, respectively. Because after scattering on the target $A$ the average spin of the particles is equal $\langle\sigma\rangle_{1}=P_{1} n_{1}$, where $P$ is polarization vector, then the target of the incident beam of particles polarized with $\langle\sigma\rangle_{1}$ spin. Therefore, the double scattering cross section can be expressed as:

$$
\sigma\left(\theta_{1}, \theta_{2}, \varphi_{12}\right)=\left(1+P_{2} \mathbf{n}_{2}\langle\sigma\rangle_{1}\right) I_{2}\left(\theta_{2}\right) I_{1}\left(\theta_{1}\right)==\left\{1+P_{2}\left(\theta_{2}\right) P_{1}\left(\theta_{1}\right) \cos \varphi_{12}\right\} I_{1}\left(\theta_{1}\right) I_{2}\left(\theta_{2}\right)
$$

where

$$
I(\theta)=|g(\theta)|^{2}+|h(\theta)|^{2}
$$

The model prediction for the polarisation of elastic $p^{12} \mathrm{C}$ scattering, corresponding to the experimental data at $p_{\mathrm{L}}=70 \mathrm{GeV}[6]$ is shown in fig.1. Note that the model predicts a large polarisation at high energies in the range of the diffraction peak.

The polarization vector of particles scattered on nuclei with zero spin is always directed perpendicular to the scattering plane. It should be noted that the polarization parameter decreases with increasing energy at small momentum transfers, since with increasing energy the region of small momentum transfers increasingly corresponds to the collinear configuration of the scattered particles, and the polarization must be zero. The analysis shows that when the preasymptotic corrections are absent, we have the zero polarisations. It is important to emphasise that the case of the nucleon-nuclei scattering the leading asymptotic terms of the spiral amplitudes is also determined by the contribution of the quark cluster with the evident replacement of $f(q)$ by the pion-nucleon scattering amplitudes. 


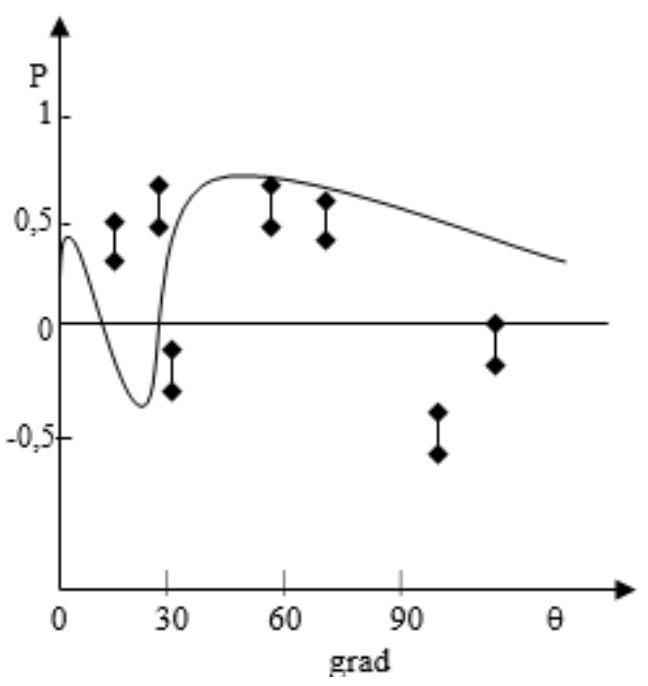

Figure 1. The polarisation of the proton in $p{ }^{12} \mathrm{C}$ reaction The solid line corresponds to the theoretical data, point data from [7].

Large values of the degree of polarization (the absolute value of the polarization vector is called the degree of polarization) are possible in the case when the interference value is comparable with the scattering cross section.

The analysis performed shows that in this case the reliable results of the predicted spin effects should be expected at an energy above $p_{\mathrm{L}}$ $=100 \mathrm{Gev}$. At a lower energy the agreement of the theory with experiment can be only qualitative.

\section{CONCLUSION}

The polarization of particles - a characteristic of the state of the particles associated with the presence of their own angular momentum spin. microparticle system is called polarized if the spatial distribution of spin orientations of the particles in the system is non-isotropic. Using different hypotheses about the property of the nucleon interaction at large distances a number of model approaches lead to the nondisappearing polarization in high -energy processes at small transfer moment.

If hadron interactions with nucleons of the target depend on the spin, the average crosssection of interaction with nucleons polarized target for hadrons, polarized parallel and antiparallel to the direction of polarization of the target will be different from each other. This means that the filtration of unpolarized beam through a polarized beam of the target will be relatively enriched hadrons with the polarization direction for which the interaction cross section of the smaller; there will be a polarization of the beam in this direction. It should be noted that the polarization parameter decreases with increasing energy at small momentum transfers, since with increasing energy the region of small momentum transfers increasingly corresponds to the collinear configuration of the scattered particles, and the polarization must zero. If polarization measurements were performed as a function of energy, it was found that the sign of the polarization varies between the quasielastic and deep inelastic regions of energy. This is explained by the interference of spin transfer from positive and negative scattering angles [8]. Different polarization signs are associated with positive and negative scattering angles and the polarization can be zero if there is a balance of scattering from both sides.

It should be noted that the mechanism producing the polarization in this model is basically a soft process, where quark-antiquark pairs are produced by a tunnelling process in the colour field and where perturbatice Quantum Chromodynamics (QCD) is not applicable.

The parameters in the spin-flip amplitude determined from one reaction allow us to obtain a wide circle of results for the polarization effects of elastic meson-nucleon scattering and charge-exchange reactions at high energies.

We consider the case when the helicity of the nucleus is not taken into account, ie, the nucleus is not polarized. It is important to emphasize that for nucleon-nuclear scattering the asymptotic terms of the amplitude helicity are also determined by the contribution of the quark cluster [9]. 


\section{REFERENCES}

[1]. Kelemen V.I., and Yu. .E. Remeta Critical minima and spin polarization in the elastic electron scattering by the mürcuri atoms J. Phys. B: At. Mol. Phys., 45 (2012) 185202.

[2]. Haque A.K.F., et al. Relativistic calculations for spin-polarization of elastic electron-mercury scattering. J. Phys. Commun., 1 (2017) 035014

[3]. Goloskokov S.V., Kroll P. The role of the quark and gluon GPDs in hard vector-meson electroproduction. Eur.Phys.J., C53 (2008) 367-384.

[4]. Glauber R. Theory of high energy hadron-nucleus collisions. High Energy Physics and Nuclear Structure, N. Y.: Plenum Press, (1970) 207.

[5]. Abdulvahabova S.G., Ahmedov R.A., Afandiyeva I.G. Journal of Physical Sience and Aplication. (US), 5-.2 (2015) 158-162.
[6]. Kessler J. Relativistic calculations for spin-polarization of elastic electron mercury scattering. Adv. At. Mol. Opt. Phys., 27 (1990) 81-163.

[7]. Kubo K.I., and Suzuki K.. The unified model for the high energy spins polarization. Proceedings of the 10th Intern. Conf. Nucl. Reaction Mechanisms, Varenna, (2003) 559.

[8]. Ahmedov R.A. Polarization Effects in Adron-Nuclei Scattering at High Energy, Cumhuriyet Science Journal, Special İssue, 37 (2016) 55-58.

[9]. Kondratyuk L., Shmatikov M.. QuarkParton Distributions in Nuclei and the EMC Effect, Pisma Zh.Eksp.Teor.Fiz. 39, (1984) 324-328; JETP Lett.(USSR) 39 (1984) $389-393$. 